\title{
Management of a Residual VSD 60 Years after One of the First Operations Worldwide
}

\author{
Yasser Yehia Hegazy ${ }^{1,2}$ Mohamed Koriem ${ }^{1} \quad$ Noha Samir Keshk-Hegazy ${ }^{1}$ Ralf Sodian ${ }^{1}$ \\ ${ }^{1}$ Mediclin Herzzentrum Lahr, Herzchirurgie, Lahr, Lahr, Germany \\ 2 Department of Cardiothoracic Surgery, Alexandria Faculty of \\ Medicine, Alexandria, Egypt \\ Address for correspondence Yasser Yehia Hegazy, MSc, MD, Mediclin \\ Herzzentrum Lahr, Herzchirurgie, Hohbergweg 277933 Lahr, Lahr \\ 77933, Germany \\ (e-mail: yasserhegazy@yahoo.com; yasser.hegazy@mediclin.de).
}

Thorac Cardiovasc Surg Rep 2021;10:e22-e24.

\begin{abstract}
Keywords

- history

- congenital heart diseases

- CHD

- cardiovascular surgery
\end{abstract}

\section{Introduction}

Ventricular septal defect (VSD) is the most common congenital cardiac anomaly, with an incidence of 2.62 per 1,000 live births, accounting for up to $40 \%$ of all congenital heart defects. ${ }^{1}$

Surgical treatment of VSD began in 1955 by Lillehei et al using human cross-circulation ${ }^{2}$ In Germany, the first surgical closure of VSD was performed by Professor Linder in 1958 in Berlin. $^{3}$

Over six decades, the surgical closure of VSD developed to be the gold standard therapy. ${ }^{4}$

However, patients are subjected later to clinical deterioration. We are presenting here one of the first patients operated upon worldwide. To our knowledge, this is the first case in literature surviving 60 years after surgical VSD closure and presenting again with a residual VSD for cardiac surgery.

\section{Case Description}

A 68-year-old male patient presented to our clinic 60 years after surgical closure of a perimembranous VSD at the University Hospital Berlin in 1959. The operation was performed by Professor Fritz Linder (-Supplementary Fig. 1) using a self-constructed heart-lung machine. The defect was $8 \times 4 \mathrm{~mm}$ and was closed through a right ventriculotomy with five simple sutures (-Supplementary Fig. 2).

The patient showed postoperatively a small residual VSD, which was well tolerated over 60 years. He played tennis regularly, and showed only a grade I dyspnea. Unfortunately, his condition began to worsen in the last year, showing progressive dyspnea (grade III), weakness, and progressive right heart failure (RHF).

The echocardiographic examination showed severe aortic and tricuspid regurgitation, moderate mitral regurgitation, and normal biventricular function. The residual VSD received

October 23, 2020

accepted

November 6, 2020
DOI https://doi.org/

$10.1055 / \mathrm{s}-0040-1722734$ ISSN 2194-7635.

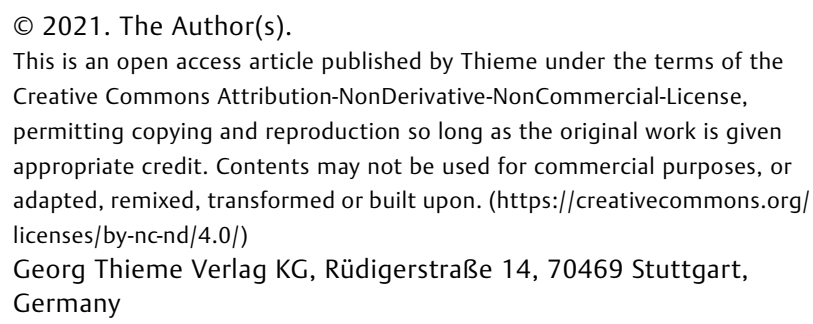



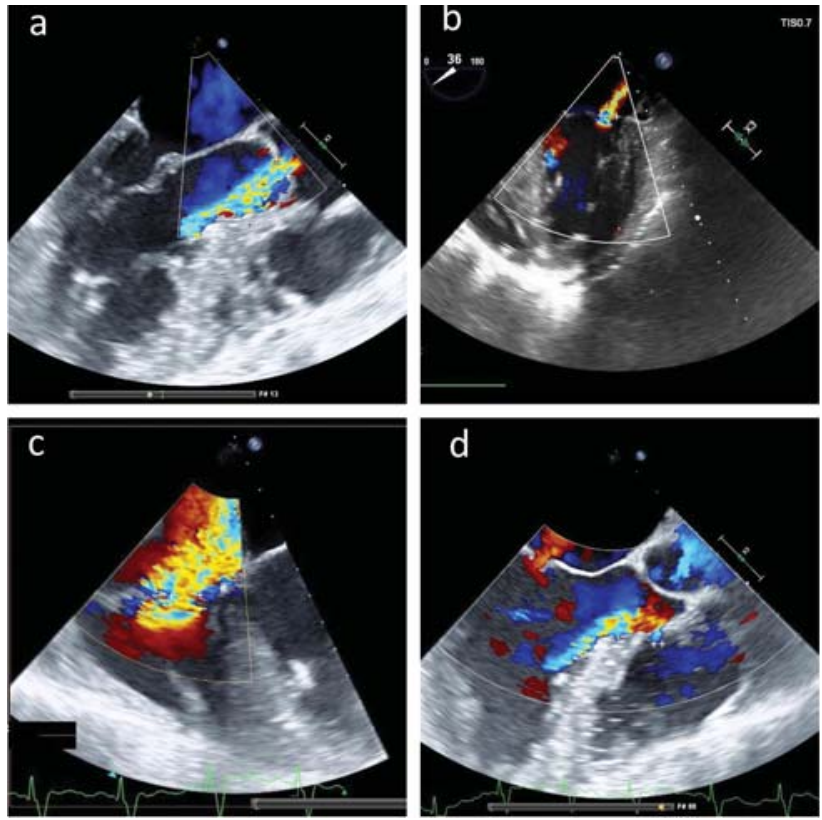

Fig. 1 Transesophageal echocardiography showing (a) severe aortic valve regurgitation ( $\mathrm{VC}=7 \mathrm{~mm}$ ), (b) moderate mitral valve regurgitation ( $\mathrm{VC}=4 \mathrm{~mm}$ ), (c) severe tricuspid valve regurgitation (VC $17 \mathrm{~mm}$ ), and (d) residual ventricular septal defect with left-to-rightshunt ( $3 \mathrm{~mm})$. VC, vena contracta.

measured $3 \mathrm{~mm}$ with a small left-to-right-shunt (-Fig. 1). The computed tomography examination showed a huge right atrium measuring $10.5 \times 7 \times 9.5 \mathrm{~cm}$ ( - Fig. 2).

Significant coronary artery stenosis could be excluded through coronary angiography. The right-sided cardiac catheterization excluded pulmonary hypertension, showing a nonsignificant left-to-right shunt (Qp:Qs $<1.5: 1$ ).

Interestingly, the patient presented to us 1 month before the operation in RHF, showing a right-to-left shunt in the bubble study, with dilatation and marked reduction in the right ventricular function.

The case was discussed interdisciplinary. Accordingly, the patient underwent aortic valve replacement (Edwards Lifesciences Pericardial Bioprosthesis, $23 \mathrm{~mm}$ ), tricuspid valve reconstruction (annuloplasty using C-E Physio Tricuspid Ring $32 \mathrm{~mm}$, and bicuspidization of the anterior and posterior leaflets), and a primary implantation of a peripheral venoar-
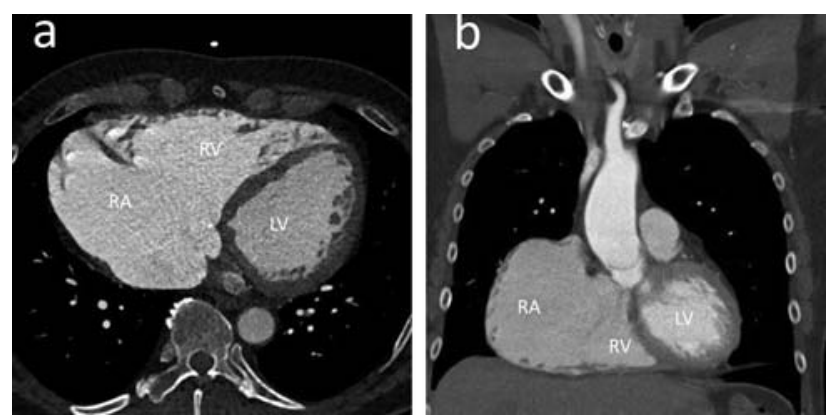

Fig. 2 Computed tomography examination of the chest with contrast showing a giant right atrium in (a) horizontal and (b) coronal sections. $L V$, left ventricle; RA, right atrium; RV, right ventricle. terial extracorporeal life support (ECLS, Maquet), to prevent potential RHF.

We decided not to close the VSD, leaving it as a vent to the right ventricle if it would fail postoperatively, especially that it could be closed later interventionally when indicated.

The intraoperative transesophageal echocardiography showed good function of the aortic bioprosthesis and the tricuspid valve showed trivial residual regurgitation after the repair.

The patient was extubated 6 hours postoperatively and the fragile unloaded right ventricle was continuously monitored till it recovered completely after 6 days. The ECLS could be weaned and explanted successfully. The patient could be discharged home 3 weeks postoperatively. He received a pacemaker 3 months postoperatively due to atrioventricular Block II and chronotropic incompetence. He could regain his activity afterwards with only a grade I dyspnea.

\section{Discussion}

Surgical treatment of congenital heart diseases emerged in the late 1950s as one of the first fields of cardiac surgery. With continuous development of surgical techniques, perfusion, and perioperative management, mortality rates improved substantially over years falling down from $30 \%$ using "Cross Circulation" to $6 \%$ within only one decade, reaching almost $1 \%$ in the last years. ${ }^{4}$

The very good long-term survival made the surgical closure of VSD the gold standard for the treatment of the indicated cases. ${ }^{4}$

However, patients operated upon for VSD are subjected to deterioration over the following decades. Menting et $\mathrm{al}^{5}$ demonstrated in their 40 years follow-up a marked deterioration over time, especially beginning from the fourth decade. Patients with impaired systolic right ventricular function increased from 1 to $17 \%$ in the fourth decade, with doubling of aortic regurgitation in the past 20 years of the study period. ${ }^{5}$ This might have been attributed to the disruption of the aortic annulus associated with direct closure of VSD, which was the first technique used. With introduction of patch closure technique, the risk of aortic regurgitation and residual VSD decreased remarkably, becoming the standard technique for most cases. ${ }^{6}$

Chronotropic incompetence is another problem with exercise tolerance after surgical VSD closure. This might be related to disturbances in the sinoatrial or atrioventricular conduction system. ${ }^{7}$

These data are consistent with our case. The patient presented 60 years postoperatively. Although he had a small residual VSD with a gradual dilatation of the right atrium, and a gradual progression of his tricuspid and aortic valve regurgitation, he remained compensated over 59 years with a minimal limitation of his physical activity. This reflects the value of regular follow-up of patients after VSD closure, apart from their general condition and the degree of success of their surgical repair, to be able to intervene in the right time.

In our case, the residual VSD was a debatable issue, for which intensive discussions among our specialists were 
conducted. Principally, residual shunts after surgical closure of VSD are not uncommon, ranging from 5 to $25 \%$, according to the type of VSD. ${ }^{8}$

One of the main concerns favoring closure of the residual VSD was the prophylaxis against endocarditis. However, Gabriels et al showed in their ultra-long-term study of 266 adult patients with VSD a $3 \%$ incidence of endocarditis in patients with nonrepaired VSD, whereas no cases of endocarditis were identified after VSD closure, even in the presence of a residual shunt. ${ }^{9}$

Other factors favoring closure were the absence of significant pulmonary hypertension and to eliminate the shunt that might have been responsible for the other pathologies.

However, factors favoring the nonclosure of the shunt were the nonsignificance of the shunt, the right-to-left shunt which was noticed in the decompensated condition, the possibility to close the defect postoperatively interventionally when needed and finally to avoid right ventricular failure if the tricuspid valve becomes competent after the repair leaving the VSD as a ventile to the right ventricle.

Owing to the high risk of RHF postoperatively, we decided to unload the right ventricle primarily using ECLS. We would like to emphasize the importance of the close monitoring of the right ventricle in such cases, as it could only slowly recover, and the patient could be weaned from ECLS after 6 days, and successfully discharged from hospital 2 weeks later.

\section{Conclusions}

Our case demonstrates the courage and persistence of our surgical grandfathers operating under very difficult conditions; they had very limited perioperative diagnostic tools, few medications, primitive postoperative care, and almost no monitoring. They have used a self-constructed heartlung-machine, and they had almost no experience regarding correction of congenital defects. Nevertheless, they could save many lives and establish this surgical treatment to be the gold standard over decades.
However, the presented case emphasizes the value of regular follow-up of patients with surgically closed VSD to be able to timely identify problems and avoid possible deterioration. Finally, in older patients with long-standing residual VSD, the primary use of ECLS might be beneficial to prevent RHF in complex clinical situations.

\section{Conflict of Interest}

None.

\section{References}

1 van der Linde D, Konings EE, Slager MA, et al. Birth prevalence of congenital heart disease worldwide: a systematic review and meta-analysis. J Am Coll Cardiol 2011;58(21):2241-2247

2 Lillehei CW, Cohen M, Warden HE, Varco RL. The direct-vision intracardiac correction of congenital anomalies by controlled cross circulation; results in thirty-two patients with ventricular septal defects, tetralogy of Fallot, and atrioventricularis communis defects. Surgery 1955;38(01):11-29

3 Linder F, Bücherl ES. Die operative Behandlung des Ventrikelseptumdefektes mit Hilfe des extracorporalen Kreislaufs. Arch F Klin Chir 1960;295:686

4 Kidd L, Driscoll DJ, Gersony WM, et al. Second natural history study of congenital heart defects. Results of treatment of patients with ventricular septal defects. Circulation 1993;87(2, Suppl):I38-I51

5 Menting ME, Cuypers JA, Opić P, et al. The unnatural history of the ventricular septal defect: outcome up to 40 years after surgical closure. J Am Coll Cardiol 2015;65(18):1941-1951

6 Backer CL, Idriss FS, Zales VR, et al. Surgical management of the conal (supracristal) ventricular septal defect. J Thorac Cardiovasc Surg 1991;102(02):288-295, discussion 295-296

7 Ohuchi H, Watanabe K, Kishiki K, Wakisaka Y, Echigo S. Heart rate dynamics during and after exercise in postoperative congenital heart disease patients. Their relation to cardiac autonomic nervous activity and intrinsic sinus node dysfunction. Am Heart J 2007;154(01):165-171

8 Bol-Raap G, Weerheim J, Kappetein AP, Witsenburg M, Bogers AJ. Follow-up after surgical closure of congenital ventricular septal defect. Eur J Cardiothorac Surg 2003;24(04):511-515

9 Gabriels C, De Backer J, Pasquet A, et al. Long-term outcome of patients with perimembranous ventricular septal defect: results from the Belgian Registry on Adult Congenital Heart Disease. Cardiology 2017;136(03):147-155 